\title{
Case Report \\ Two level reverse cross finger flaps to cover soft tissue defects of a finger using a single donor finger
}

\author{
Ashan Fernando', Amila Siriwardena ${ }^{2}$ \\ ${ }^{1}$ National Hospital, Sri Lanka, ${ }^{2}$ Teaching Hospital, Anuradhapura, Sri Lanka.
}

Keywords: Reverse cross finger flap, soft tissue defect

Corresponding Author: Ashan Fernando, E-mail:< ashan.fernando.4@gmail.com> (iD) https://orcid.org/0000-0002-0562-8564

Received: September 2017, Accepted revised version December 2018, Published: December 2018

Competing Interests: Authors have declared that no competing interests exist

(C) Authors. This is an open-access article distributed under a Creative Commons Attribution-Share Alike 4.0 International License (CC BY-SA 4.0), which permits unrestricted use, distribution, and reproduction in any medium, provided the original author and source are attributed and materials are shared under the same license.

\section{Introduction}

The hand is a versatile structure and plays a key role in many activities. However, it is more prone to injuries because of its frequent use. Management of hand injuries is difficult as many intricate anatomical structures join to form a functional unit. The skin provides a robust cover for all the vital structures of the fingers. Therefore, restoring soft tissue cover to the finger following trauma is pivotal in the management.

Finger injuries are common due to its frequent use and peripheral location. Obtaining early soft tissue cover is essential to optimise anatomical and functional outcomes. Soft tissue cover of the fingers can be obtained from a variety of options ranging from simple split skin grafts, pedicle flaps or even small free flaps. The type of soft tissue cover utilized to cover the defect depends on the site, extent of injury and the expertise and experience of the surgeon. Reverse cross finger flap is a versatile option to cover soft tissue defects of the dorsum of the finger. The following is an interesting case where two soft tissue defects of the ring finger were covered by two reverse cross finger flaps taken from the adjacent middle finger. Reverse cross finger flap is a very reliable and resilient flap to cover dorsal soft tissue defects. Obtaining cover for soft tissue defects at two levels of a finger using a single donor finger has not been reported.

\section{Case Presentation}

A 48-year-old healthy male farmer, sustained a crush injury to the right little and ring fingers. It was his dominant hand. There were open fractures of the phalanges of the ring and little fingers. It was managed with wound debridement and Kirschner wire (K- wire) fixation.

After a week, the patient was re-admitted with severe surgical site infection which resulted in wound debridement and partial amputation of the little finger. Following control of infection, the patient was left with a partially amputated little finger and a ring finger with two level dorsal soft tissue defects, each measuring $1 \mathrm{~cm} \times 2 \mathrm{~cm}$ in size. The 
defects were exposing the proximal interphalangeal joint (PIP) and the bone of the distal phalanx (Figure 1).

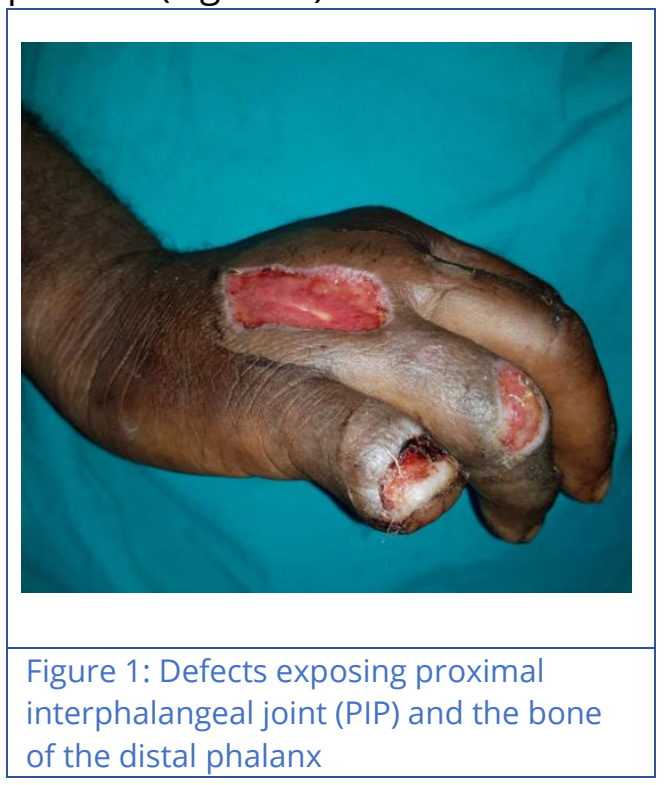

Terminalisation of the little finger was done. The two dorsal skin defects of the ring finger were covered by two reverse cross finger flaps taken from the middle finger. Secondary soft tissue defects and the de-epithelialised flaps were covered with split skin grafts (Figures 2,3 \&4).

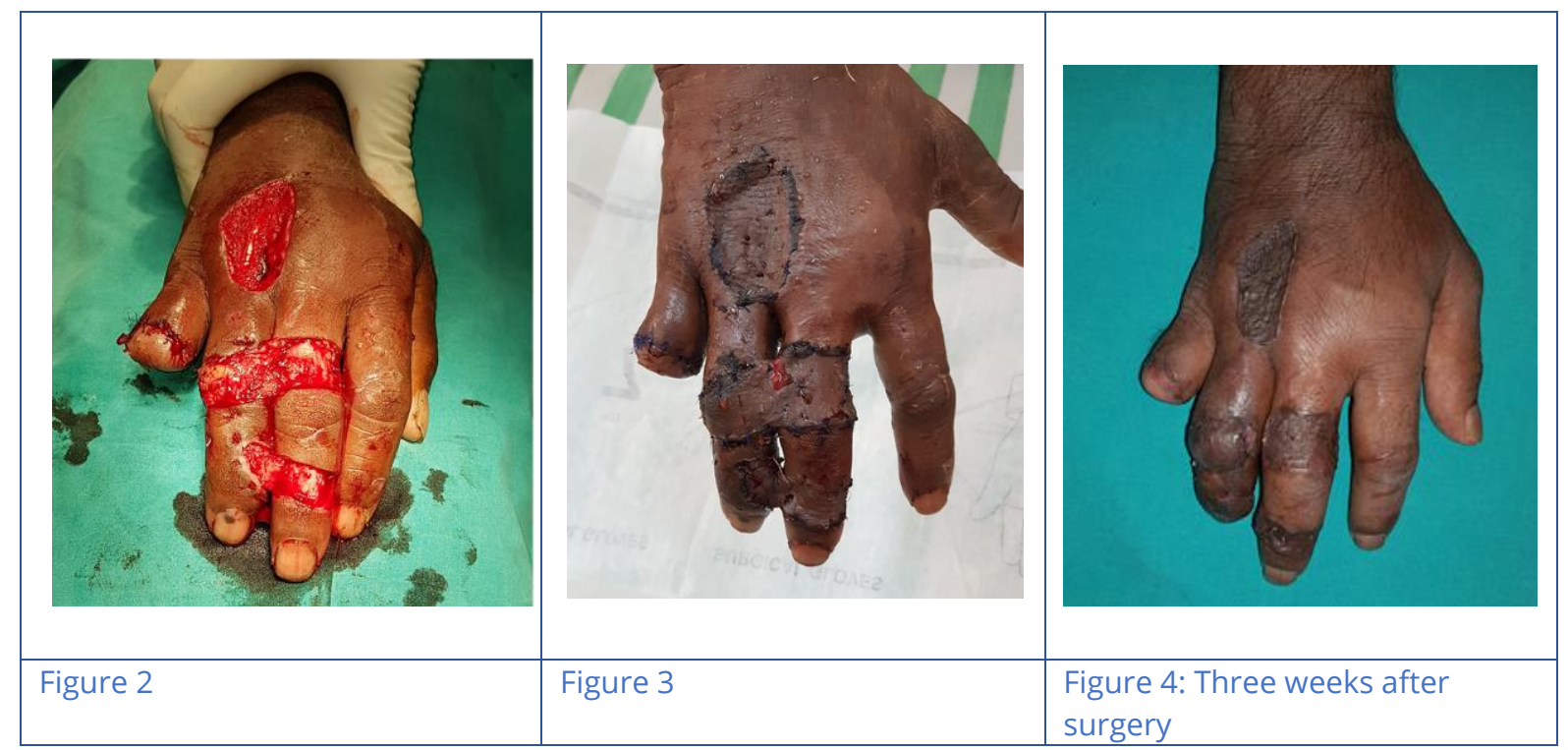

The patient recovered without any significant post-operative complications and the soft tissue bridges were disconnected after 3 weeks.

\section{Discussion}

Primary soft tissue cover to the finger is important to protect its intricate anatomy. Skin cover prevents desiccation of underlying soft tissues and infection of bone and joint spaces. Obtaining early soft tissue cover permits early mobilization as well as minimizes 
granulation and secondary fibrosis which leads to stiffness. It also leads to less scar formation leading to a better functional and cosmetic outcome.

Soft tissue cover may be established by a variety of options. The "reconstructive ladder" or levels of increasingly complex plastic surgery for soft tissue cover ranges from the technically easy to very demanding procedures. However, there is a shift from the reconstructive ladder to a "reconstructive elevator" or "tool box" where the most appropriate option is chosen [1]. Reverse cross finger flap is a robust and aesthetically acceptable option to cover dorsal soft tissue defects. Prior to any soft tissue procedure, it is vital to perform an adequate wound debridement. This helps to clean potential sources of infection and also aids in healing. A good debridement is the most important initial step in obtaining soft tissue cover.

A commonly used method of soft tissue cover of fingers is to use cross finger flaps taken from adjacent fingers. To cover the dorsal surface reverse cross finger flaps are utilized after de-epithelialisation. This patient posed a challenge in obtaining soft tissue cover to the ring finger as the adjacent little finger was amputated. The task of obtaining cover was more difficult as the ring finger had two soft tissue defects measuring $1 \mathrm{~cm} \times 2 \mathrm{~cm}$ in size. Literature shows that two defects of the same finger can be covered by cross finger flaps taken from either side. It also shows how a single finger can donate cross finger flaps to either side of adjacent fingers [2,3]. However, since the little finger was partially amputated this option was not available. Therefore, two dorsal reverse cross finger flaps were harvested from the middle finger to cover the defects of the ring finger.

The reverse cross finger flap can also be utilized to give bulk after releasing scars and also to reconstruct fingertip avulsions. The flap provides bulk and a resilient surface for secondary skin grafting. Being a sensate flap, it aids the functionality of the fingers. Cross finger flaps carry donor site morbidity which includes decreased range of motion of finger and decreased grip strength. The cosmetic outcomes can be improved by using full thickness grafts instead of split skin grafts [4]. Our patient had a certain degree of stiffness.

\section{Conclusion}

Even though cross finger flaps may carry significant donor site morbidity it is a very reliable and resilient flap. Therefore, when the need for two cross finger flaps arise using a single finger as a donor site, it appears to be an acceptable option.

\section{Declaration}

Ethics approval was obtained from the Ethics Review Committee, Teaching Hospital, Peradeniya. Informed written consent was obtained from the patient for publication of this case report and accompanying images. Patient's data has been kept confidential to protect his identity.

\section{Acknowledgments}

The authors would like to thank Dr Amila Siriwardane and the staff of the Orthopaedic Unit, Teaching Hospital, Peradeniya, for their continuous support in patient care. 


\section{References}

1. Brody GS, Cloutier AM, Woolhouse F. The fingertip injury-an assessment of management. Plastic and Reconstructive Surgery. 1960;26(1):80-90. https://doi.org/10.1097/00006534-196007000-00007

2. Kaleli T, Ersozlu S, Ozturk C. Double reverse-flow island flaps for two adjacent finger tissue defect. Archives of orthopaedic and trauma surgery. 2004;124(3):157-60. https://doi.org/10.1007/s00402-003-0621-x

3. Moosa AA-hA. Double cross-finger flaps: a novel technique for management of ring avulsion injuries. Annals of plastic surgery. 2010;64(4):409-11. https://doi.org/10.1097/SAP.0b013e3181b142d5

4. Koch $\mathrm{H}$, Kielnhofer $\mathrm{A}$, Hubmer M, Scharnagl E. Donor site morbidity in cross-finger flaps. British journal of plastic surgery. 2005;58(8):1131-5.

https://doi.org/10.1016/j.bjps.2005.04.047 